AJHSE Vol: 2 (2): 183-195, 2021

DOI: 10.52417/ajhse.v2i2.177

Accepted Date: Sept. 30, 2021

(C) 2021. CC License 4.0

www.ajhse.org

\title{
KNOWLEDGE OF MICROBIAL CONTAMINATION OF SPHYGMOMANOMETERS IN HEALTHCARE FACILITIES IN BENIN CITY
}

\author{
${ }^{* 1}$ Okaekwu, A. E., ${ }^{2}$ Usifoh, S. F. \& ${ }^{3}$ Babaiwa, U. F. \\ ${ }^{*}$ I\&2 Department of Clinical Pharmacy and Pharmacy Practice, University of Benin, Benin City, Nigeria. \\ ${ }^{3}$ Department of Pharmaceutical Microbiology, University of Benin, Benin City, Nigeria \\ *Corresponding Author's E-mail: okaekwuagnes@ gmail.com Phone: +2349057778016
}

\begin{abstract}
$\mathrm{N}$ osocomial infections are infections that patients acquire while receiving treatment for other health conditions within a healthcare setting or facility. This study aims to determine the level of awareness of healthcare providers on the role sphygmomanometers play in the spread of nosocomial infections and to isolate microorganisms in sphygmomanometer cuffs used in healthcare facilities. A structured, selfadministered questionnaire was designed and administered to healthcare practitioners of two tertiary hospitals and community pharmacies in Benin City. Microbial contamination of sphygmomanometer cuffs was investigated following the standard isolation and identification techniques for microorganisms. A total of 217 responded; $27.2 \%$ pharmacists, $33.2 \%$ doctors and $39.6 \%$ nurses. The majority (50.2\%) were between the ages of $20-30$ years. $65.4 \%$ were females and $51.6 \%$ were single. Ninety-four percent (94\%) of the total respondents said that microorganisms are present in the inner cuffs of sphygmomanometers, $76 \%$ said microorganisms on the cuffs are sources of nosocomial infections while $80.6 \%$ said patients can be infected with the use of sphygmomanometers. A total of 192 swabbed samples were collected from 64 cuffs in the healthcare facilities, $46.5 \%$ were bacteria and $53.5 \%$ fungi. The most isolated organisms were candida species 42(21\%), Staphylococcus aureus 41(20.5\% of which 28(68.3\%) were methicillin resistant.), Mucor 34(17\%), Aspergillus species 23(11.5\%). Ninety four percent (94\%) of respondents had good knowledge that blood pressure cuffs play a role in the spread of nosocomial infections. The sphygmomanometer cuffs were contaminated with pathogenic microorganisms implicated in nosocomial infections.
\end{abstract}

KEYWORDS: Sphygmomanometers, blood pressure cuffs, Nosocomial infections, Healthcare Associated infections, Hospital acquired infections, Healthcare acquired infections, Healthcare acquired illness.

LICENSE: This article by African Journal of Health, Safety and Environment (AJHSE) is licensed and published under the Creative Commons Attribution License 4.0 International License, which permits unrestricted use, distribution, and reproduction in any medium, provided this article is duly cited.

COPYRIGHT: The Author(s) completely retain the copyright of this published article.

OPEN ACCESS: The Author(s) approves that this article remains permanently online in the open access (OA) model

QA: This Article is published in line with "COPE (Committee on Publication Ethics) and PIE (Publication Integrity \& Ethics)". 


\section{INTRODUCTION}

Nosocomial infections or healthcare associated infections are infections that patients acquire while receiving treatment for other health conditions within a healthcare setting or facility. They are usually not present in the patient at the time of admission to the healthcare facility (Azeez-Akande, 2012; Hassan et al., 2017). Bacteria account for most cases of nosocomial infections (often $80 \%$ of all cases). However, fungi, viruses and parasites, are also causative organisms (Hassan et al., 2017).

Nosocomial infections can be spread in a number of ways; through direct or indirect contact, droplet, airborne, common vehicles or vector-borne. Transmission through the sphygmomanometers is by indirect contact with the patients' skin where the organisms can then move to other sites of the body to cause harm.

Sphygmomanometers are used on multiple patients in medical facilities, and during each use microorganisms can settle on the cuffs of the sphygmomanometers which can spread from one patient to another since their routine disinfection is not always performed (Matsuo et al., 2013)

The objectives of this study were to determine the knowledge of healthcare providers on the role sphygmomanometers play in the spread of nosocomial infections and to isolate microorganisms in sphygmomanometer cuffs used in healthcare facilities.

While many studies have been carried out on the microbial contamination of sphygmomanometers used on patients in hospital settings in developed and developing countries (United Kingdom, Ethiopia, India), not much has been done particularly in Nigeria. No work has also been done in community settings like the community pharmacies in Nigeria. This research work did not only consider the bacterial isolation but also the fungal isolation of the sphygmomanometers used in both hospital and community settings.

\section{MATERIALS AND METHODS}

\section{STUDY DESIGN}

This was a cross-sectional study conducted in major health facilities in Benin City. Sampling places included Central Hospital, University of Benin Teaching Hospital, and randomly selected and highly busy Community Pharmacies from the four Local Government Areas in Benin City (Egor, Ovia, Oredo and Ikpoba-Okha). The sample size from the hospital was based on the number of sphygmomanometers available in the various units visited.

\section{DATA COLLECTION}

A structured, self-administered questionnaire was designed and administered to healthcare practitioners (pharmacists, doctors and nurses) of two tertiary hospitals and community pharmacies in Benin City. The questionnaire consisted of three segments; sociodemographics (age, marital status, religion, profession and years of experience), knowledge of microbial presence on the blood pressure cuffs of sphygmomanometers and disinfection practice by the healthcare practitioners. Data generated were both quantitative and qualitative and analyzed using SPSS version 22 and presented using descriptive statistics such as frequencies and percentages of the identified organisms. Differences between the proportions were assessed using Chi square analysis. P-value $\leq 0.05$ was considered statistically significant. Ethical approval was obtained from Central Hospital Benin City (A732/T/1), University of Benin Teaching hospital (ADM/E 22/A/VOL II/14775) and administrative approval from the pharmacies. 


\section{SAMPLE COLLECTION}

Three sterile swab sticks were used for each sphygmomanometer and before being used, were moistened with $0.9 \%$ normal saline. The first two sticks were used to wipe the inner surface (the part that comes in direct contact with the patient's upper arm) and the outer surface (the part the healthcare provider touches while handling the blood pressure cuffs) of the sphygmomanometer cuffs respectively. The third sterile swab stick was used to wipe the inner surface again, but this time, after disinfecting it with $70 \%$ isopropyl alcohol and allowed to stand for 10minutes, following slightly modified method of Jeyakumari et al. (2016). All swabbed samples were immediately transported to the Pharmaceutical Microbiology Laboratory of the University of Benin, Benin City for analysis.

Serial dilutions of the swabbed samples were carried out by aseptically transferring the swab sticks into $10 \mathrm{ml}$ diluent (sterile distilled water) and subsequently inoculated into 1: 10, 1: 100, and 1: 1000 diluents. The dilutions were inoculated on already set nutrient agar (Titan Biotech Limited, India) plates using Miles and Misra method allowed to diffuse and then incubated at 37 degrees Celsius for 48 hours.

For the fungi isolation, the dilutions were transferred into Petri dishes and molten potato dextrose agar (Titan Biotech Limited, India) was poured on each plate using the pour plate method, allowed to set and then incubated at room temperature for 48 hours. After 48 hours, the plates were observed for growth, the colonies were counted and the results recorded. Gram staining was done and based on the Gram stain reaction, the following biochemical tests; catalase, slide and tube coagulase, oxidase, citrate, indole, sugar and hemolytic tests were performed to identify the bacteria isolates while the fungi isolates were identified using the Atlas (Bernward and Gabriele 1980).

\section{RESULTS AND DISCUSSION SOCIODEMOGRAPHIC DATA}

The Cronbach's Alpha of reliability of the questionnaire was 0.650 . A total of 217 respondents (pharmacists, doctors, and nurses) filled the questionnaire; $27.2 \%$ were pharmacists, $33.2 \%$ were doctors and 39.6\% nurses. Majority of the respondents, $50.2 \%$ were between the ages of 20 - 30 years, $65.4 \%$ were females and $51.6 \%$ were single. Almost all 95.4\% were Christians and more than an average of the respondents $126(58.1 \%)$ had less than 5 years working experience, 44(20.3\%) had between 6-10years experience, 22(10.1\%) 11-15years experience, 12(5.5\%) had 16-20 experience and $13(6.0 \%)$ had over 20years experience.( Table 1 ) 
Table 1: Socio demographic data of Respondents

\begin{tabular}{|c|c|c|}
\hline Variable & Frequency $(n=217)$ & Percentage \\
\hline \multicolumn{3}{|l|}{ Age } \\
\hline $20-30$ & 109 & 50.2 \\
\hline $31-40$ & 61 & 28.1 \\
\hline $41-50$ & 36 & 16.6 \\
\hline 51 and above & 11 & 5.1 \\
\hline \multicolumn{3}{|l|}{ Gender } \\
\hline Male & 75 & 34.6 \\
\hline Female & 142 & 65.4 \\
\hline \multicolumn{3}{|l|}{ Marital status } \\
\hline Single & 112 & 51.6 \\
\hline Married & 101 & 46.5 \\
\hline Divorced & 1 & 0.5 \\
\hline Widowed & 3 & 1.4 \\
\hline \multicolumn{3}{|l|}{ Religion } \\
\hline Christian & 207 & 95.4 \\
\hline Muslim & 9 & 4.1 \\
\hline Traditional religion & 1 & 0.5 \\
\hline \multicolumn{3}{|l|}{ Profession } \\
\hline Doctors & 72 & 33.2 \\
\hline Nurses & 86 & 39.6 \\
\hline \multicolumn{3}{|l|}{ Years of Experience } \\
\hline$<5$ years & 126 & 58.1 \\
\hline $6-10$ & 44 & 20.3 \\
\hline $11-15$ & 22 & 10.1 \\
\hline $16-20$ & 12 & 5.5 \\
\hline$>20$ years & 13 & 6.0 \\
\hline
\end{tabular}

KNOWLEDGE OF MICROBIAL CONTAMINATION OF SPHYGMOMANOMETERS FROM THE THREE HEALTHCARE FACILITIES

Ninety four percent $(94 \%)$ of the respondents said that microorganisms were present in the inner cuffs of sphygmomanometers, (76\%) said that microorganisms on the cuffs of sphygmomanometers were sources of nosocomial infections and (80.6\%) said that patients can be infected with the use of sphygmomanometers 
On the measures to reducing the microbial loads on the BP cuffs of sphygmomanometers, $87.6 \%$ of the respondents said that disinfecting the patient's upper arm before using the sphygmomanometer can reduce microbial load, $88.0 \%$ said disinfecting the inner surface of the blood pressure can reduce the microbial load, while $95.9 \%$ said wearing of hand gloves by healthcare practitioners and then $76.0 \%$ said placing a thin sterile physical barrier between patients' upper arms and the BP cuffs, can reduce microbial load and transmission of nosocomial infection (Table 2).

Table 2: Knowledge of Microbial contamination of sphygmomanometers from the three health facilities

\begin{tabular}{|c|c|c|}
\hline Variable & YES $\mathrm{F}(\%)$ & NO $\quad F(\%)$ \\
\hline $\begin{array}{l}\text { Microorganisms are present in the inner cuffs of } \\
\text { sphygmomanometers }\end{array}$ & $204(94)$ & $15(6)$ \\
\hline $\begin{array}{l}\text { Microorganisms on the cuffs of sphygmomanometers are } \\
\text { sources of nosocomial infections }\end{array}$ & $165(76)$ & $52(24)$ \\
\hline Patients can be infected with the use of sphygmomanometers & $175(80.6)$ & $42(19.4)$ \\
\hline $\begin{array}{l}\text { Microorganisms from the inner layer of the BP cuffs of } \\
\text { sphygmomanometers are solely from patients }\end{array}$ & $72(33.2$ & $145(66.8)$ \\
\hline $\begin{array}{l}\text { Microorganisms from the outer layer of the BP cuffs of } \\
\text { sphygmomanometers are solely from the healthcare }\end{array}$ & $31(14.3)$ & $186(85.7)$ \\
\hline $\begin{array}{l}\text { Microorganisms from the outer layer of the BP cuffs can be } \\
\text { introduced by the healthcare practitioner }\end{array}$ & 169 (77.9) & $48(22.1)$ \\
\hline $\begin{array}{l}\text { Disinfecting the patients' upper arms before using the } \\
\text { sphygmomanometers can reduce the transmission of } \\
\text { microbes }\end{array}$ & $190(87.6)$ & $27(12.4)$ \\
\hline $\begin{array}{l}\text { Disinfecting the inner surface of BP cuffs can reduce or } \\
\text { completely kill the microorganisms }\end{array}$ & $191(88)$ & $26(12)$ \\
\hline $\begin{array}{l}\text { Wearing of gloves by health care practitioners can reduce the } \\
\text { transmission of microbes to/from patients and health care } \\
\text { practitioners }\end{array}$ & $208(95.9)$ & $9(4.1)$ \\
\hline $\begin{array}{l}\text { Placing a thin sterile physical barrier between the patients' } \\
\text { upper arm and the BP cuff can reduce transmission }\end{array}$ & $165(76)$ & $52(24)$ \\
\hline
\end{tabular}

In this study, (94\%) of healthcare practitioners had good knowledge that sphygmomanometers are carriers of microorganisms. However, this knowledge did not correspond with their disinfection practice as only $19.8 \%$ of the healthcare practitioners claimed to disinfect the sphygmomanometers while $80.2 \%$ did not disinfect. The high microbial load observed on the blood pressure cuffs of the sphygmomanometers during the microbial isolation in the laboratory could be due to the fact that the healthcare providers who make use of the medical instrument did not actually engage in the disinfection of the sphygmomanometers. Among those who claimed to disinfect, $19.4 \%$ used $70 \%$ isopropyl alcohol. This finding was similar to that of Umegbolu (2019) in which 83.8\% of the health workers (doctors and nurses) were aware that stethoscopes and sphygmomanometers can act as sources of nosocomial infections but only $5 \%$ of healthcare practitioners in the healthcare facilities investigated disinfected their sphygmomanometers. In another study by Sangita and Lokendra (2017) on bacteriological assessment of stethoscopes (non-critical medical devices) used by healthcare workers in a tertiary care center in Nepal, $96.7 \%$ of healthcare workers were aware that stethoscopes could transmit microorganisms from patient to patient. However, in their study, 
$72.1 \%$ (88 healthcare workers) reported cleaning their stethoscopes while in this study; majority had never disinfected their sphygmomanometers before. Also, in both studies, methylated spirit which is also known as isopropyl alcohol was the most commonly used disinfectant.

Regarding what the respondents do before handling the sphygmomanometers, $59.5 \%$ of respondents in Central hospital wear gloves while in University of Benin Teaching Hospital, $44.3 \%$ of respondents wash their hands, and in Community pharmacies, the majority (61.1\%) said they do nothing, meaning they neither wear hand gloves nor wash their hands before handling the sphygmomanometers. This also buttress the fact that most of these healthcare practitioners are aware that sphygmomanometers harbour microorganisms but do not disinfect the instrument before using it on multiple patients. For this reason, more education and enlightenment should be done to enable the healthcare practitioners engage more in the disinfection of the instrument to reduce microbial load and by extension reduce the risk of transmission of nosocomial infections from patient to patient. Majority of the healthcare practitioners use the sphygmomanometers on 5-20 patients daily. In the hospital settings, 36.9\% of respondents from Central hospital and $38.6 \%$ from UBTH have used the sphygmomanometer for 5years and above while in community pharmacies $38.9 \%$ of the respondents have used it for 1-2 years.

In Central hospital, $66.7 \%$ of respondents said they use the same Sphygmomanometer for patients with obvious skin infections and those without skin infections while in the community pharmacies and University of Benin Teaching Hospital, 52.8\% and 61.4\% respectively, claimed they don't use the same sphygmomanometer for both patients $(\mathrm{p}$-value $=0.0002)$. This finding however, didn't reflect the practice on ground as most of the units visited only had one sphygmomanometer, they used in checking every patient that comes for medical consultation in the hospitals. This could literally translate to the fact that these healthcare providers use the same sphygmomanometer on both categories of patients. For instance, in the dermatology unit investigated in the University of Benin Teaching Hospital, there are patients with obvious skin infections and those whose skin infections have remitted but still come for followup, because of the limited number of sphygmomanometers, these patients are still checked with the same sphygmomanometers used for those with obvious skin infections.

The majority of the respondents do not take any precautionary measures to avert the transmission of microorganisms from infected to non-infected patients when using the sphygmomanometer (Table3). 
Table 3: Comparison of Practice on the use of Sphygmomanometers in the different health care centers

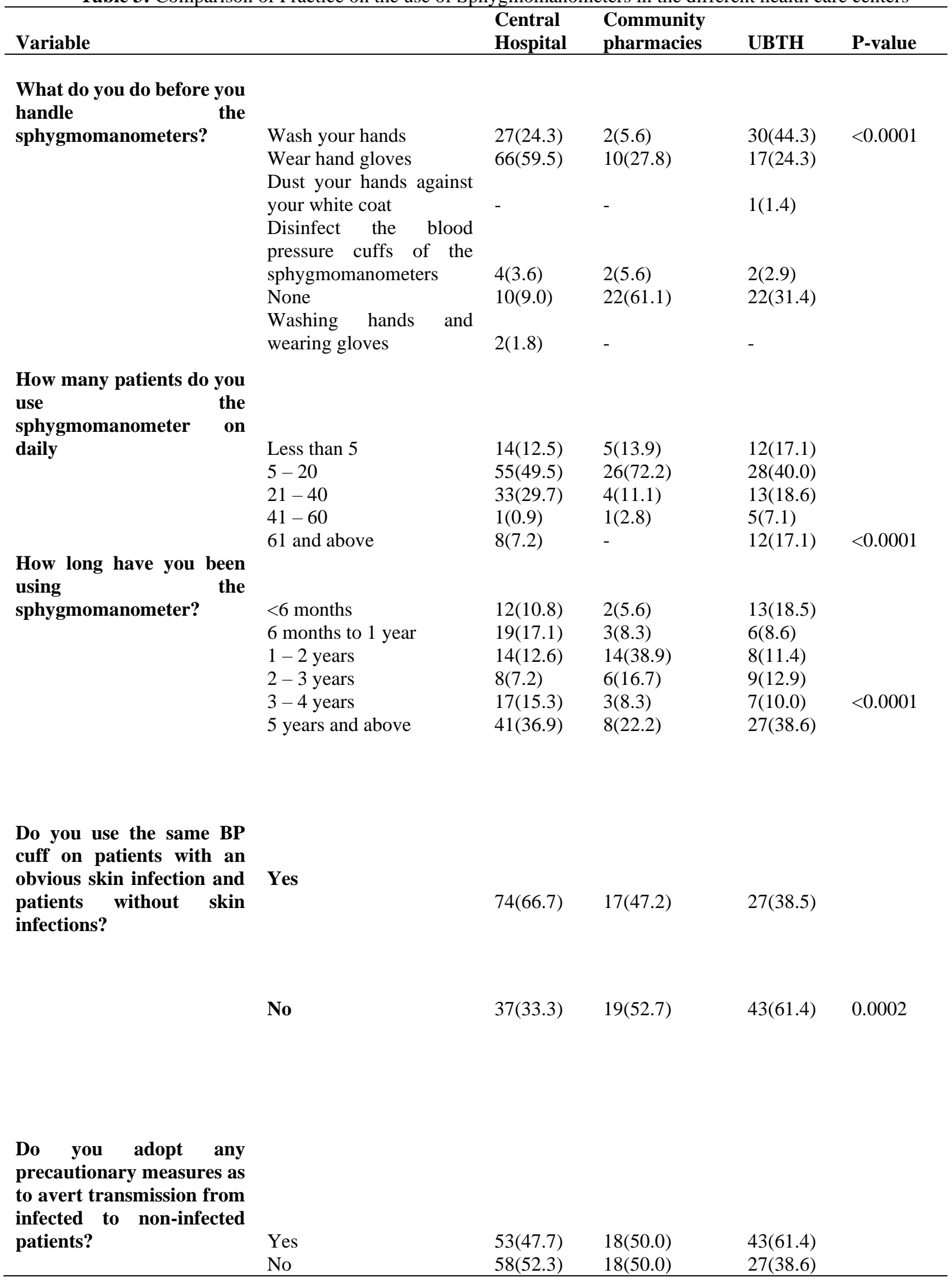




\section{What precautionary measure do you take to avert this transmission?}

Use a disposable BP cuff

Place a physical barrier between the patients' upper arm and the BP cuff
11(9.9)

$16(14.4)$
$3(8.3)$

$8(11.4)$

5(13.9)

16(22.9)

Disinfect the patients' upper arm before using the BP cuff on the patient Use of hand sanitizer $7(6.3)$ $5(13.9)$

None 48(43.2) 16(44.4)

On the disinfection practices of the respondents from the three healthcare facilities, the majority $(75.0 \%, 81.4 \%$ and 84.7\% respectively from Community pharmacies, UBTH and Central hospital) do not disinfect the sphygmomanometer before using it on patients. Also, majority of respondents had never disinfected the sphygmomanometer before in the course of their practice (55.6\%, 71.4 and 72.1 from community pharmacies, UBTH and central respectively). For the minority who did disinfect, the commonly used disinfectant was $70 \%$ isopropyl alcohol. This finding was in line with a study by Agam et al(2018), out of the 62 health workers (doctors, nurses and medical students) who participated in the study, 53.22\% had never disinfected their stethoscopes before and among those who disinfected, $86.2 \%$ used alcohol-based disinfectant while none of the respondents disinfected their stethoscopes after seeing each patient.

Lack of time and lack of access to disinfectants were the major barriers to disinfecting the blood pressure cuffs of sphygmomanometers (Table 4). However, lack of time shouldn't be a barrier to disinfecting the blood pressure cuffs of sphygmomanometers because from this study, disinfecting with 70\% isopropyl alcohol and allowing it to stand for 10 minutes before using it on the patients was found to eliminate the microorganisms and in few cases drastically reduced the microbial load on the sphygmomanometers. This was in line with a study done by Jeyakumari et al, (2016) to investigate the bacterial colonization of sphygmomanometers. In their study, they found out that disinfecting the blood pressure cuffs with $70 \%$ isopropyl alcohol either reduced or eliminated the microorganisms present on the blood pressure cuffs. So, allocating 10 minutes every working day to disinfect the blood pressure cuffs before starting the day's work will go a long way in reducing the microbial loads on these sphygmomanometers and thus reduce the risk of transmission of nosocomial infections among patients. 
Table 4: Comparison of disinfection practices of sphygmomanometers in the different healthcare facilities.

\begin{tabular}{|c|c|c|c|c|}
\hline Variable & $\begin{array}{l}\text { Central } \\
\text { Hospital }\end{array}$ & $\begin{array}{l}\text { Community } \\
\text { pharmacies }\end{array}$ & UBTH & p-value \\
\hline \multicolumn{5}{|l|}{$\begin{array}{l}\text { Do you disinfect the BP cuff before } \\
\text { using it? }\end{array}$} \\
\hline Yes & $17(15.3)$ & $9(25.0)$ & 13(18.6) & \\
\hline No & $94(84.7)$ & $27(75.0)$ & $57(81.4)$ & 0.2012 \\
\hline \multicolumn{5}{|l|}{ When did you disinfect it last? } \\
\hline Today & 14(12.6) & $2(5.6)$ & $7(10.0)$ & \\
\hline Yesterday & $4(3.6)$ & $1(2.8)$ & 1(1.4) & \\
\hline Last week & $3(2.7)$ & $2(5.6)$ & $6(8.6)$ & \\
\hline 2 weeks ago, & $3(2.7)$ & $5(13.9)$ & $2(2.9)$ & 0.0008 \\
\hline Last month & $7(6.3)$ & $6(16.7)$ & $4(5.7)$ & \\
\hline Never disinfected before & $80(72.1)$ & $20(55.6)$ & $50(71.4)$ & \\
\hline \multicolumn{5}{|l|}{ How often do you disinfect } \\
\hline After every use on a patient & 13(11.7) & $3(8.4)$ & $6(8.5)$ & \\
\hline After the day's activity & $5(4.5)$ & $2(5.6)$ & $5(7.1)$ & \\
\hline Weekly & $4(3.6)$ & $3(8.3)$ & $4(5.7)$ & \\
\hline Monthly & $6(5.4)$ & $7(19.4)$ & $6(8.6)$ & 0.0421 \\
\hline Never disinfected before & $83(74.8)$ & $19(52.8)$ & $49(70.0)$ & \\
\hline \multicolumn{5}{|l|}{ Disinfectant used } \\
\hline 70\% Isopropyl alcohol & $30(27.0)$ & $10(27.8)$ & 13(18.6) & \\
\hline Hydrogen peroxide & $3(2.7)$ & $4(11.1)$ & $4(5.7)$ & \\
\hline Izal & - & - & - & \\
\hline Wash with soap water & $6(5.4)$ & $2(5.6)$ & $7(10.0)$ & \\
\hline Hand sanitizer & $2(1.8)$ & - & $3(4.3)$ & \\
\hline None & $70(63.1)$ & $20(55.6)$ & $43(61.4)$ & \\
\hline \multicolumn{5}{|c|}{$\begin{array}{l}\text { Which of these is a barrier to you for } \\
\text { not disinfecting the blood pressure } \\
\text { cuffs? }\end{array}$} \\
\hline Lack of time & 43(38.7) & $13(36.1)$ & $20(28.5)$ & \\
\hline Forgetfulness/laziness & $5(4.5)$ & $3(8.3)$ & $3(4.3)$ & \\
\hline $\begin{array}{l}\text { Lack of knowledge regarding best } \\
\text { disinfectant }\end{array}$ & $6(5.4)$ & $1(2.8)$ & $11(15.7)$ & $<0.0001$ \\
\hline Lack of access to disinfectants & $26(23.4)$ & $2(5.6)$ & $14(20.0)$ & \\
\hline $\begin{array}{l}\text { Fear of damaging the } \\
\text { sphygmomanometer }\end{array}$ & $9(8.1)$ & $7(19.4)$ & $8(11.4)$ & \\
\hline Sharing of sphygmomanometer & $17(15.3)$ & $1(2.8)$ & $7(10.0)$ & \\
\hline $\begin{array}{l}\text { Ignorance of sphygmomanometer being } \\
\text { a means of transmitting infections }\end{array}$ & $7(6.3)$ & $9(25.0)$ & $6(8.6)$ & \\
\hline
\end{tabular}

FREQUENCY OF MICROBIAL ISOLATES IN THE DIFFERENT HEALTHCARE FACILITIES

In total, 93 bacteria and 107 fungi isolates were identified from the three healthcare facilities. There was microbial growth in $57(89.1 \%)$ sphygmomanometers and in 7 (10.9\%) sphygmomanometers there was no growth. Potentially pathogenic strains isolated were Candida species 42 (21.0\%) Staphylococcus aureus 41(20.5\%) of which 28 (68.3\%) were methicillin-resistant, Mucor 34(17.0\%), Aspergillus species 23(11.5\%), Bacillus species,18(9.0\%), Coagulase Negative Staphylococcal species 14(7.0\%). Other organisms isolated were Bacteriodes species, Pseudomonas species, Citrobacter species, Klebsiella species, Escherichia coli, Penicillum species, Trichophyton species, and Cryptococcus 
species all of which accounted for $14.0 \%$ as shown in the table below. The most commonly isolated bacteria were Staphylococcus aureus while candida species were the most frequent fungi isolated. The inner surfaces of the blood pressure cuffs of the sphygmomanometers were more contaminated than the outer surfaces. This was similar to the findings of the study carried out by Baruah et al., (2008) in which the inner surfaces were also more contaminated than the outer surfaces. It was also found that the $70 \%$ isopropyl alcohol was effective in either reducing the microbial load or eliminating the microorganisms on the blood pressure cuffs.

Bacteria, fungi, viruses, parasites are all responsible for health care associated infections, however, bacteria have been found to be the most implicated (Hassan et al, 2017). In this particular study, on the overall, fungi were the most isolated organisms accounting for 53.5\%. Among the bacteria isolated, Staphylococcus aureus was the most isolated which was in line with studies done by Fitsum et al. (2019), on non-critical healthcare tools as a potential source of healthcare-acquired bacterial infections and Uneke and Ijeoma (2011), in which thermometers and blood pressure cuffs used in different units of the hospital were investigated for microbial growth.

The table 5 below showed the overall microorganisms isolated; with Staphylococcus aureus,

Bacillus species, Coagulase Negative Staphylococcal species, Bacteriodes species, Pseudomonas species, Citrobacter species, Klebsiella species and Escherichia coli being the bacteria isolated and Candida species, Mucor, Aspergillus species, Penicillum species, Trichophyton species, Cryptococcus species were the fungi isolated. However, the organisms isolated from this study and those of other studies sited (Baruah et al., 2008, Uneke and Ijeoma 2011, Umegbolu 2019). varied from one healthcare facility to the other. This could be attributed to variation in geographical location, the way the sphygmomanometers are being handled by the different healthcare practitioners and also the healthcare environment in which the studies were conducted. 
Table 5: Overall Frequency of microbial isolates in the three healthcare facilities

\begin{tabular}{|c|c|c|}
\hline Organisms isolated & Frequency & Percentage \\
\hline Staphylococcus aureus & 41 & 20.5 \\
\hline Bacillus species & 18 & 9.0 \\
\hline Coagulase Negative & 14 & 7.0 \\
\hline \multicolumn{3}{|l|}{ Staphylococcal species } \\
\hline Bacteriodes species & 8 & 4.0 \\
\hline Pseudomonas species & 7 & 3.5 \\
\hline Citrobacter species & 3 & 1.5 \\
\hline Klebsiella species & 1 & 0.5 \\
\hline Escherichia coli & 1 & 0.5 \\
\hline Candida species & 42 & 21 \\
\hline Mucor & 34 & 17 \\
\hline Aspergillus species & 23 & 11.5 \\
\hline Penicillum species & 5 & 2.5 \\
\hline Trichophyton species & 2 & 1.0 \\
\hline Cryptococcus species & 1 & 0.5 \\
\hline Total & 200 & 100 \\
\hline
\end{tabular}

\section{CONCLUSION}

A high proportion of the respondents had good knowledge that the blood pressure cuffs can play a role in the spread of infections. However, they did not engage in good disinfection practice of the sphygmomanometers. Thus, more education and enlightenment should be done to enable the healthcare practitioners engage more in the disinfection of the instrument to reduce microbial load and by extension reduce the risk of transmission of nosocomial infections This study has also confirmed that most of the sphygmomanometers used in the investigated healthcare facilities were contaminated with pathogenic organisms that are implicated in healthcare-associated infections as the organisms isolated are found to cause serious systemic infections that require the hospitalization of the patients to effectively treat.

\section{ACKNOWLEDGEMENT}

My gratitude goes to the Head of Department, Pharmaceutical Microbiology, University of Benin; Dr. (Mrs.) U.F. Babaiwa for her laboratory support. To the laboratory technologist, Mr. Aisagbonbuomwan Wilfred, you are indeed 
one in a million, thank you so much for bringing your expertise to the table. I learnt so much from you during this period. God bless you immensely sir.

\section{COMPETING INTERESTS}

The authors declare that they have no competing interests.

\section{REFERENCES}

Agam B, Sarath R.S, Bhavna D.B, Kajal Gupta, Shashank P (2018). To Assess the Stethoscope Cleaning Practices, Microbial Load and Efficacy of Cleaning Stethoscopes with Alcohol-based Disinfectant in a Tertiary Care Hospital. Journal of Infection Prevention 20(1):46-50.

Azeez-Akande, O. (2012). Emerging and Re-Emerging Infectious Agents of Nosocomial Diseases-The Need for Review of Hospital Policy and Control Strategies. Bayero Journal of Pure and Applied Sciences. 5(2): 1925.http://dx.doi.org/10.4314/bajopas.v5i2.3

Baruah J.K, Gratrix A, Dibb W and Madeo M (2008). Blood pressure cuffs as a potential fomite for transmission of pathogenic micro- organisms: A prospective study in a university teaching hospital. British Journal of Infection Control, $9(4): 20$

Bernward R and Gabriele H (1980). Introducing Mycology by Examples. Berlin: Schering A.G, 140pp.

Fitsum W, Desalegn A, Dereje M, and Mulatu A (2019). Non-critical healthcare tools as a potential source of healthcare-acquired bacterial infections in eastern Ethiopia: A hospital-based cross- sectional study. Sage Open Medicine, 7: 1-10 DOI: 10.1177/2050312118822627

Hassan A.K, Fatima K.B, Riffat M (2017). Nosocomial infections: Epidemiology, Prevention, Control and Surveillance. Asian Pacific Journal of Tropical Biomedicine, 7(5):478-482.

Jeyakumari D, Nagajothi S, Praveen Kumar R, Ilayaperumal G. and Vigneshwaran S. (2016) Bacterial colonization of blood pressure cuff: A potential Source of Pathogenic Organism: A Prospective study in a teaching hospital. International Journal of Medical and Health Research, 2(6): 35-37.

Matsuo M, Oie S, Furukawa H (2013). Contamination of Blood Pressure Cuffs by Methicillin-Resistant Staphylococcus aureus and Preventive Measures. Irish Journal of Medical Science, 182:707-709DOI $10.1007 / \mathrm{s} 11845-013-0961-7$

Miles A.A, Misra S.S, Irwin J.O, (1938). The Estimation of the Bactericidal power of the Blood. The Journal of Hygiene.38(6):732-749. Retrieved on the $4^{\text {th }}$ November 2019 org > wiki https://en.m.wikipedia

Monk S. (2010). Disposable Blood Pressure Cuffs: You cannot afford to use them. Sun Tech Med White Paper 1-2.

Robert A.W and Rabih O.D. (2001). Device- Associated Infections: A Macro Problem that starts with Micro adherence. Clinical Infectious Diseases 33(9):1567-1572. 
Sangita T. and Lokendra B.S(2017). Bacteriological assessment of stethoscopes used by healthcare workers in a tertiary care Centre of Nepal. Biomed Central Research Notes 10:353 DOI 10.1186/s13104-017-2677-7. Available at:www.biomedcentral.com

Tagoe DNA, Baidoo S.E, Agede C. (2011). Potential Sources or Transmission of Healthcare Associated Infections in the Volta Regional Hospital in Ghana. Ghana Medical Journal 45(1):22-26.

Umegbolu Emmanuel I. (2019). The Roles of Stethoscopes and Sphygmomanometers in Hospital-Acquired Infections: A Case Study of some District Hospitals in Enugu State, Southeast Nigeria. International Journal of Research in Medical Sciences, 7(5):1686-1691 DOI: http://dx.doi.org/10.18203/2320-6012.ijrms20191659

Uneke C.J. and Ijeoma P.A. (2011). The Potential for Transmission of Hospital-Acquired Infections by Non-critical Medical Devices: The Role of Thermometers and Blood Pressure Cuffs. World Health and Population 12(3):6-12.

World Health Organization (2011). Report on the Burden of Endemic Health Care-Associated Infection Worldwide. World Health Organization.

https://apps.who.int/handle/10665/80135 